Syntax Literate : Jurnal Ilmiah Indonesia p-ISSN: 2541-0849

e-ISSN : 2548-1398

Vol. 5, No. 5 Mei 2020

\title{
STABILITASI FASA KALSIUM PIROFOSPAT PADA TEMPERATUR TINGGI DENGAN PENAMBAHAN ZIRKONIA
}

\section{Ihsanul Huda, Retno Kusumaningrum, Galuh Sukmarani dan Alfian Noviyanto}

Program Studi Magister Teknik Mesin Universitas Mercu Buana

Email: ihsanulhuda3@gmail.com, aning@nano.or.id, galuhsukmarani@nano.or.id dan a.noviyanto@nano.or.id

\section{Abstract}

Calcium Pirofospat is an excellent biomaterial for use as a substitute for broken or cracked bones or teeth. Calcium Pirofospat is biocompatible, bioactive and has a chemical composition that is close to the composition of human bones and teeth. However, this biomaterial has the disadvantage of being low in mechanical properties when used to accept heavy loads. Enhancement of the mechanical properties of calcium pyropospate can be done by adding zircon material. Therefore, this study conducted a study of calcium pyrophosphate phase change by the addition of zircon at high temperatures. Zirconia composition added by 5\% and $10 \%(w / w)$ Mixing of calcium pyrophosphate was carried out using High Energy Milling (HEM) with Ball Powder Ratio (BPR) of 5: 1 for 30 minutes. The mixture is then heated at a temperature of $1000{ }^{\circ} \mathrm{C}$ for 60 minutes. The results of characterization using XRD showed that heating treatment can decompose calcium pyrophosphate and the formation of $\mathrm{CaZrO}_{3}$. Warming also causes larger particle sizes. The SEM results show the size of the CPP TA microstructure which was originally $590 \pm 43 \mathrm{~nm}$ to CPP TAZ5 $1.212 \pm 268 \mathrm{~nm}$ and CPP TAZ10 $1.324 \pm$ $384 \mathrm{~nm}$. Whereas for CPP TB which was originally $455 \pm 32 \mathrm{~nm}$ to CPP TBZ5 1.112 $\pm 546 \mathrm{~nm}$ and CPP TBZ10 $1.123 \pm 392 \mathrm{~nm}$.

Keywords: Calcium Pyrophosphate, Zirconia, High Energy Milling.

\section{Abstrak}

Kalsium Pirofospat adalah biomaterial yang sangat baik untuk digunakan sebagai pengganti tulang atau gigi yang rusak ataupun retak. Kalsium Pirofospat bersifat biokompatibel, bioaktif dan memiliki komposisi kimia yang mendekati komposisi pada tulang dan gigi manusia. Namun biomaterial ini memiliki kekurangan yaitu sifat mekanisnya yang rendah apabila digunakan untuk menerima beban yang berat. Peningkatan sifat mekanik kalsium pirofospat dapat dilakukan dengan menambahkan material zirkon. Oleh karena itu, pada penelitian ini dilakukan kajian perubahan fasa kalsium pirofospat dengan penambahan zirkon pada temperatur tinggi. Komposisi zirkonia yang ditambahkan sebesar $5 \%$ dan $10 \%$ (w/w). Pencampuran kalsium pirofosfat dilakukan menggunakan High Energy Milling (HEM) dengan Ball Powder Ratio (BPR) sebesar 5:1 selama 30 menit. Campuran selanjutnya dipanaskan pada temperatur $1000^{\circ} \mathrm{C}$ selama 60 menit. Hasil karakterisasi menggunakan XRD menunjukan bahwa perlakuan pemanasan dapat mendekomposisi kalsium pirofosfat dan terbentuknya $\mathrm{CaZrO}_{3}$. Pemanasan juga 
menyebabkan ukuran partikel semakin besar. Hasil SEM menunjukkan ukuran mikrostruktur CPP TA yang semula 590 $\pm 43 \mathrm{~nm}$ menjadi CPP TAZ5 $1.212 \pm 268 \mathrm{~nm}$ dan CPP TAZ10 1.324 $\pm 384 \mathrm{~nm}$. Sedangkan untuk CPP TB yang semula $455 \pm 32 \mathrm{~nm}$

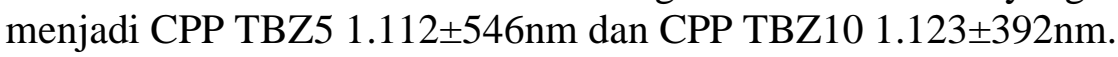

Kata kunci: Kalsium Pirofospat, Zirkonia, High Energy Milling.

\section{Pendahuluan}

Kalsium pirofospat merupakan mineral yang mengandung ion kalsium, oksigen dan fospat (Su et al., 2017). Kalsium pirofospat dapat digunakan sebagai biomaterial implan tulang dan gigi (Darwis \& Warastuti, 2013) karena bersifat biokompatibel, bioaktif dan memiliki komposisi kimia yang mendekati dari komposisi keduanya (Lee et al., 2009). Sintetis kalsium pirofospat menyerupai dari Hidroksiapatit yang telah lama dipelajari dan hasilnya telah digunakan sebagai biomaterial (Lin, Liaw, Hon, \& Wang, 1995).

Besarnya potensi yang ada pada kalsium pirofospat dalam bidang biomedik, berkembanglah beberapa teknik untuk membuatnya. Metode sintetis yang sering dipergunakan adalah metode wet-chemistry. Metode wet-chemistry yang dikenal adalah metode presipitasi (Pawarangan \& Yusuf, 2018), hydrothermal (Xu, Wang, Yang, \& Tang, 2001), sol-gel (Rissa \& Priatmoko, 2012) dan solvothermal (Ediati, Mudjahid, \& Pangastuti, 2015). Pada penelitian kali ini metode solvothermal dipilih karena kepraktisannya.

Kalsium Piropospat bersifat rapuh dan tingkat stabilitas kekuatannya rendah (Zhou et al., 2016) namun mempunyai kelebihan dibanding dengan hidroksiapatit yaitu tingkat kelarutan dalam tubuh lebih tinggi sehingga secara bertahap dapat menggantikan sebagai tulang yang baru (Geuli, Metoki, Eliaz, \& Mandler, 2016).

Untuk meningkatkan fungsi kalsium pirofospat sebagai biomaterial yang memiliki sifat mekanik yang baik maka diperlukan modifikasi struktur melalui pembentukan komposit dengan bahan lain sebagai penguat. Beberapa bahan penguat yang sering digunakan adalah Zirkonia, Alumina, Spinel, dan Mullit (Asri, Septawendar, \& Sunendar, 2016).

Zirkonia memiliki karakteristik biokompatibilitas, ketangguhan retak dan ketangguhan patah yang baik (Bulut, Erkmen, \& Kayali, 2016). Zirkonia adalah bahan dari keramik yang mempunyai sifat keras dan juga memiliki sifat tahan terhadap temperatur tinggi (Baidya, 2013).

Penelitian tentang Hidroksiapatit Zirkonia pada pemanasan $1000^{\circ} \mathrm{C}$ telah dilakukan dan menghasilkan fasa baru yaitu zirkonia tetrahedral (Karlina et al., 2017). Sedangkan pengaruh zirkonia pada kalsium pirofosfat hingga saat ini belum banyak diteliti. Oleh karena itu, pada penelitian ini akan dilakukan kajian penambahan zirkonia pada biomaterial kalsium pirofospat dan pengaruh pemanasan suhu tinggi terhadap fasa campuran. 


\section{Metode Penelitian}

Penelitian ini menggunakan serbuk Biomaterial Kalsium Pirofospat dari limbah cangkang telur ayam dan cangkang telur bebek, yang dibuat dengan menggunakan metode solvothermal. Kedua Biomaterial ini mempunyai dimensi $\pm 0,5 \mu \mathrm{m}$ sebagai matrik utama dan serbuk Zirkonia sebagai bahan campuran (Asri et al., 2016).

Serbuk Zirkonia yang ditambahkan 5\% dan 10\% (w/w) ke serbuk Kalsium Pirofospat, seperti pada tabel 1 dibawah ini.

Tabel 1

Komposisi Serbuk Kalsium Pirofospat Zirkonia

\begin{tabular}{c|c|c|c}
\hline No & Jenis kompositCPP $\%$ & $\mathrm{ZrO}_{2} \%$ & Kode \\
\hline 1 & Telur Ayam 95 & 5 & CPP TAZ5 \\
\hline 2 & Telur Ayam 90 & 10 & CPP TAZ10 \\
\hline 3 & Telur Bebek 95 & 5 & CPP TBZ5 \\
\hline 4 & Telur Bebek 90 & 10 & CPP TBZ10 \\
\hline
\end{tabular}

Homogenisasi campuran dilakukan menggunakan alat High Energy Milling (HEM) model Shaker Mil (Asri et al., 2016) dengan Ball Powder Ratio sebesar 5:1 satuan berat selama 30 menit pada setiap komposisinya. Kemudian dilanjutkan dengan proses pemanasan pada temperatur $1000^{\circ} \mathrm{C}$ selama 60 menit dengan kecepatan pemanasan dan pendinginan sebesar $5^{\circ} \mathrm{C} /$ menit.

Untuk menganalisis fasa pada campuran tersebut digunakan pengujian menggunakan X-Ray Diffraction (XRD, PANalytical, Netherlands) dan pengamatan struktur mikro pada material hasil pengujian dengan menggunakan Scanning Elektron Microscopy (SEM, Quanta 650,FEI,USA).

\section{Hasil dan Pembahasan}

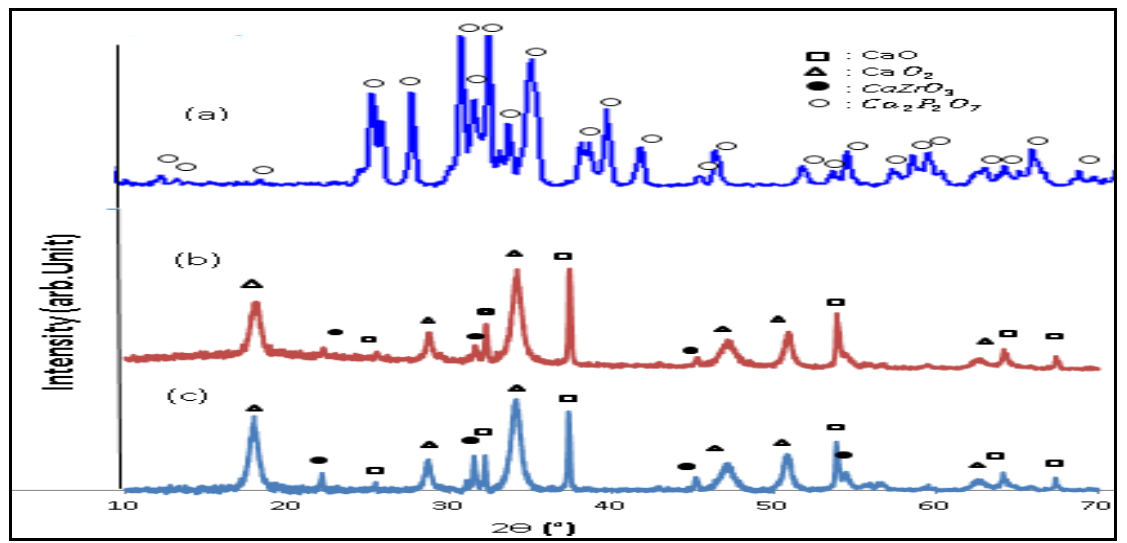

Gambar 1

Pola Hasil Pengujian XRD (a)Sintetis CPP Telur Ayam (b) CPP TAZ5 (b) CPP TAZ10

Gambar 1 memperlihatkan hasil dari pengujian menggunakan XRD untuk sampel CPP TAZ5 dan CPP TAZ10 setelah pemanasan $1000^{\circ} \mathrm{C}$. Hasil dari analisis $\mathrm{XRD}$, menunjukkan adanya fasa baru $\mathrm{CaO}$ dan $\mathrm{CaO}_{2}$ yang terbentuk pada sampel $\mathrm{CPP}$ 
TAZ5 dan CPP TAZ10 setelah dilakukan pencampuran dan pemanasan $1000^{\circ} \mathrm{C}$, dengan fasa sampingan yang terbentuk adalah $\mathrm{CaZrO}_{3}$. Terbentunya fasa baru disebabkan oleh adanya reaksi yang terjadi pada kalsium pirofospat dan zirkonia yang membentuk $\mathrm{CaO}_{2}$ dan $\mathrm{CaZrO}_{3}, \mathrm{CaO}_{2}$ kemudian tereduksi membentuk $\mathrm{CaO}$. Reaksi dekomposisi kalsium pirofospat dapat dilihat pada persamaan reaksi (1),(2) dan (3). Hasil analisis menunjukkan bahwa semakin besar komposisi zirkonia yang ditambahkan maka intensitas fasa $\mathrm{CaZrO}_{3}$ yang terbentuk semakin tinggi. Dekomposisi fasa dapat dilihat pada persamaan reaksi dibawah ini.

$$
\begin{array}{ll}
\mathrm{Ca}_{2} P_{2} \mathrm{O}_{7}+2 \mathrm{ZrO}_{2} & =\mathrm{P}_{2} \mathrm{O}_{5}+2 \mathrm{CaZrO}_{3} . \\
\mathrm{Ca}_{2} P_{2} \mathrm{O}_{7} & =2 \mathrm{CaO}_{2}+P_{2} \mathrm{O}_{3} \ldots \ldots \ldots . . . \\
2 \mathrm{CaO}_{2} & =2 \mathrm{CaO}+\mathrm{O}_{2}(\mathrm{~g}) \ldots \ldots . .
\end{array}
$$

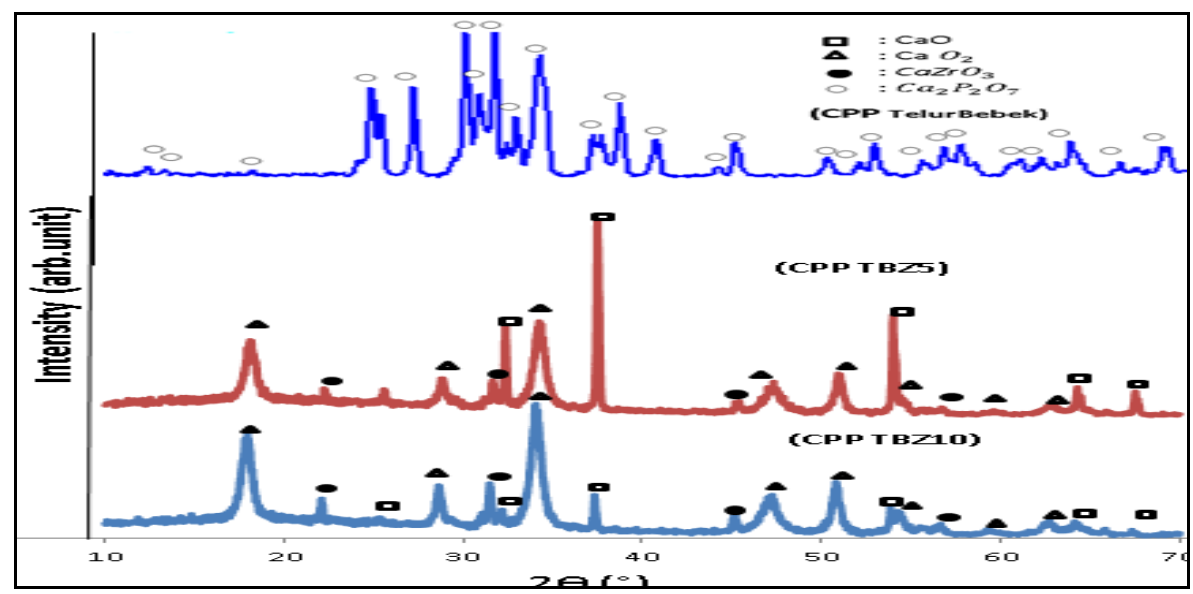

Gambar 2

Pola Hasil Pengujian XRD CPP Telur Bebek, CPP TBZ5 dan CPP TBZ10

Gambar 2 menunjukkan hasil dari pengujian menggunakan XRD untuk sampel CPP TBZ5 dan CPP TBZ10 setelah proses pencampuran dan pemanasan $1000^{\circ} \mathrm{C}$. Hasil dari analisis XRD menunjukkan bahwa CPP TBZ5 dan CPP TBZ10 memperlihatkan perubahan dekomposisi dari fasa sebelumnya yaitu $\mathrm{Ca}_{2} \mathrm{P}_{2} \mathrm{O}_{7}$ ke bentuk fasa $\mathrm{CaO}$ dan $\mathrm{CaO}_{2}$, dengan fasa sampingan yang terbentuk $\mathrm{CaZrO}_{3}$. Terbentuknya fasa $\mathrm{CaZrO}_{3}$ terlihat dari meningkatnya peak fasa $\mathrm{CaZrO}_{3}$ pada CPP TBZ10. Semakin banyak penambahan komposisi Zirkonia maka semakin meningkat pula peak fasa $\mathrm{CaZrO}$ 3. Peningkatan fasa juga terjadi pada fasa $\mathrm{CaO}_{2}$. Penambahan zirkonia yang banyak menyebabkan reaksi pembentukan $\mathrm{CaZrO}_{3}$ semakin banyak pula, baik pada CPP TA maupun CPP TB. 


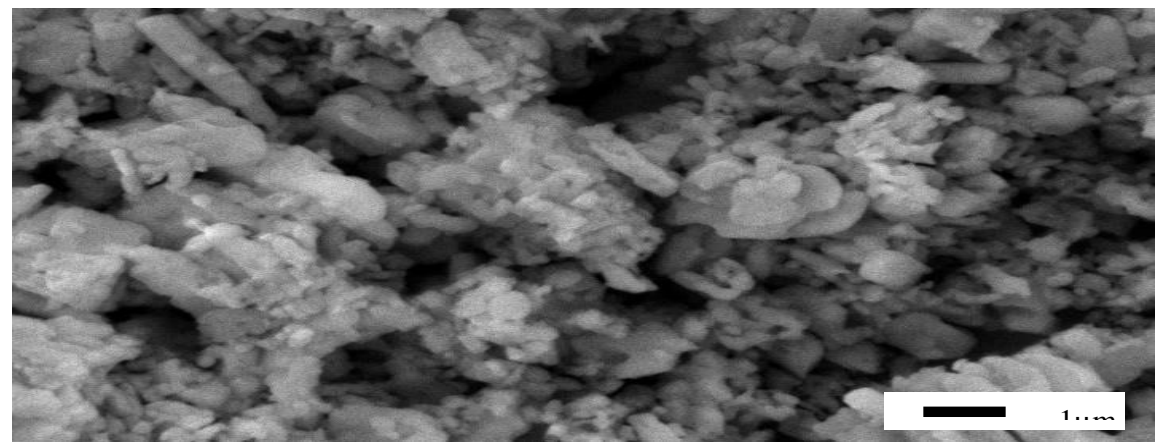

(a)

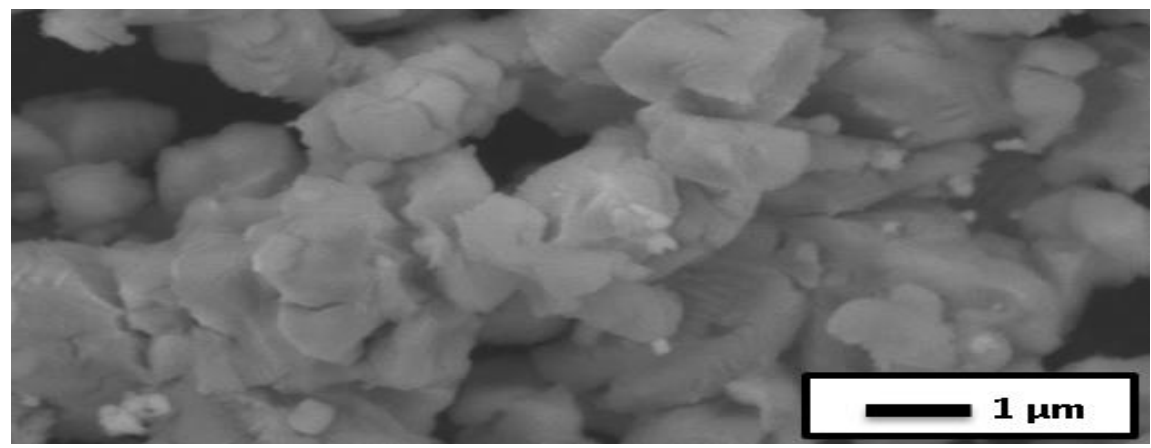

(b)

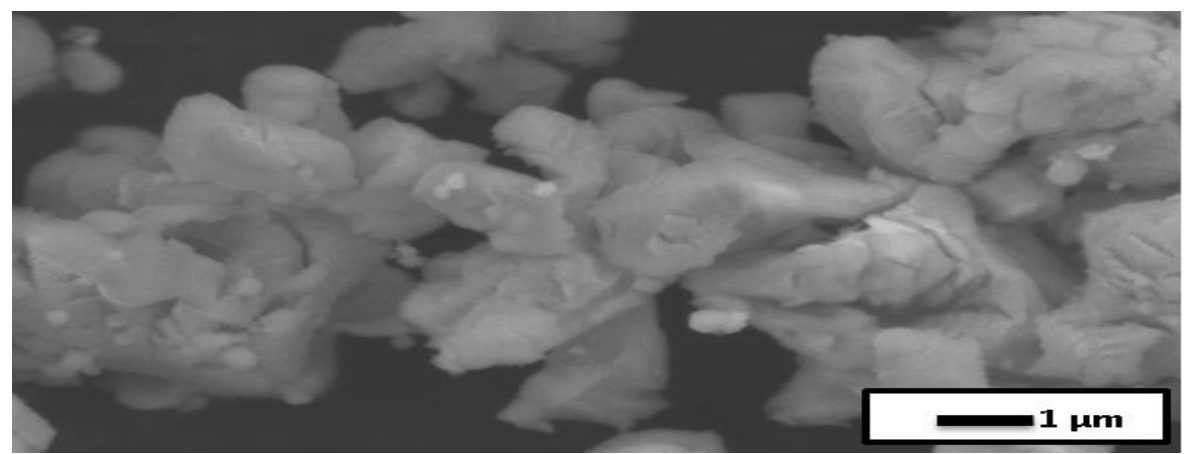

(c)

Gambar 3

Hasil SEM dari (a) CPP TA (b) CPP TAZ5, dan (c) CPP TAZ10 setelah pemanasan $1000^{\circ} \mathrm{C}$

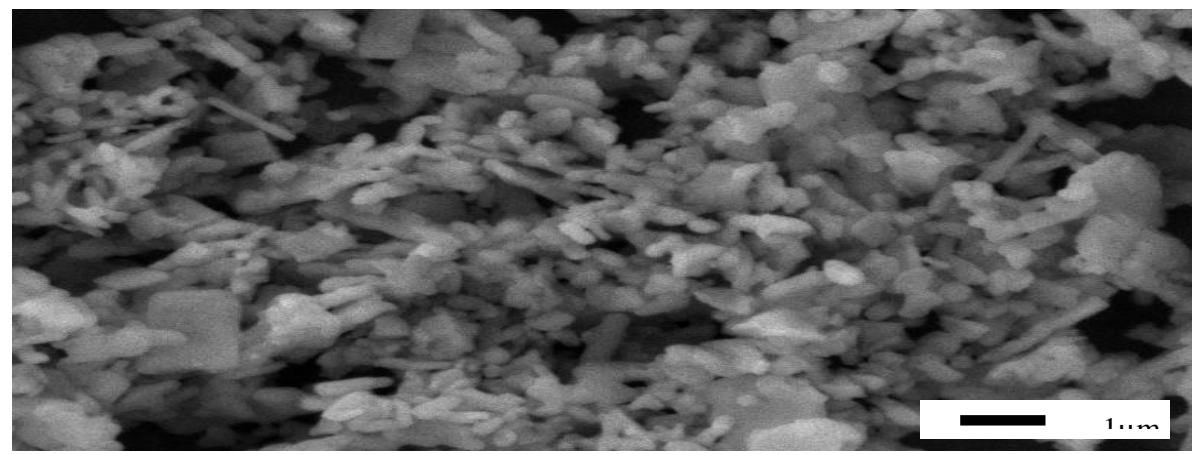

(d) 


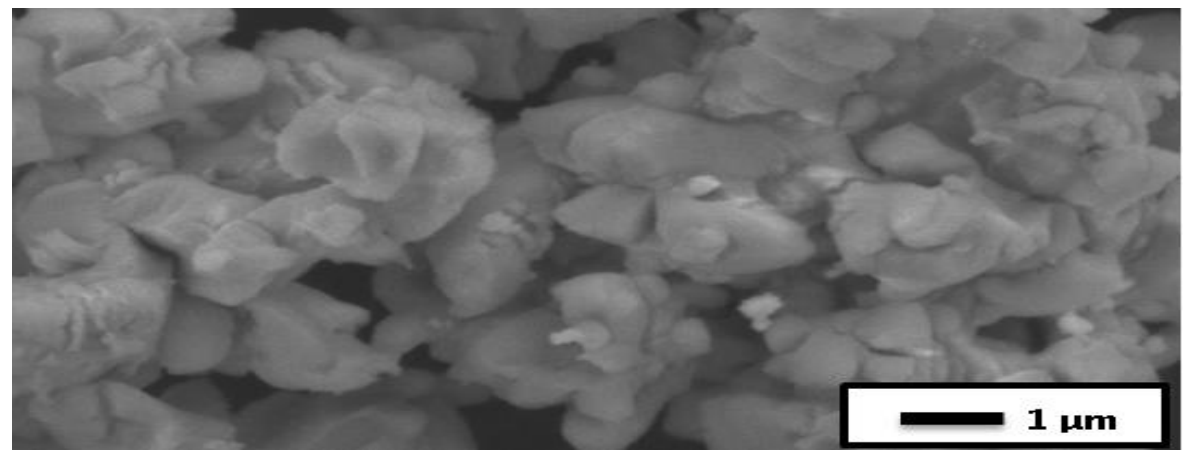

(e)

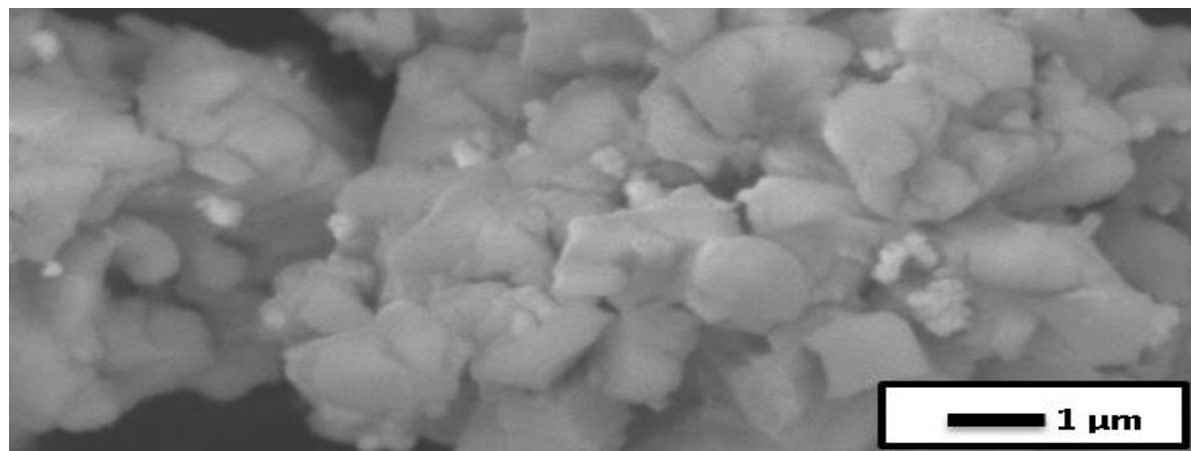

(f)

\section{Gambar 4 \\ Hasil SEM dari (d) CPP TB (e) CPP TBZ5 dan (f) CPP TBZ10 setelah pemanasan $1000^{\circ} \mathrm{C}$}

Gambar 3 dan 4 menunjukkan bahwa ukuran mikrostruktur dari CPP TA5, CPP TBZ5 dan ukuran mikrostruktur CPP TA10, CPP TBZ10 lebih besar dan lebih seragam dibanding ukuran mikrostruktur CPP TA dan CPP TB. Hal ini disebabkan oleh pemanasan $1000^{\circ} \mathrm{C}$ dan penambahan Zirkonia. Semakin banyak penambahan Zirkonia maka ukuran mikrostruktur nya semakin besar. Seperti terlihat pada tabel 2 dibawah ini.

\section{Tabel 2}

Hasil Pengukuran Partikel Campuran CPP

\begin{tabular}{ccccccc}
\hline Komposisi & CPP TA & CPP TAZ5 & CPP TAZ10 & CPP TB & CPP TBZ5 & CPP TBZ10 \\
\hline Ukuran & $590 \pm 43$ & $1.212 \pm 268$ & $1324 \pm 384$ & $455 \pm 32$ & $1.112 \pm 546$ & $1.123 \pm 392$ \\
Partikel & $\mathrm{nm}$ & $\mathrm{nm}$ & $\mathrm{nm}$ & $\mathrm{nm}$ & $\mathrm{nm}$ & $\mathrm{nm}$ \\
\hline
\end{tabular}

Berdasarkan pengujian XRD bisa dilihat bahwa semakin banyak fasa yang terdapat pada bahan maka ukuran mikrostrukturnya semakin besar. Hal ini disebabkan oleh faktor pemanasan dan campuran zirkonia. Sesuai dengan hasil pengujian XRD yang menunjukkan fasa setelah proses pemanasan $1000^{\circ} \mathrm{C}$ dan penambahan campuran Zirkonia baik CPP TAZ5, CPP TBZ5 atau CPP TAZ10, CPP TBZ10 mendapatkan fraksi fasa yang beragam. Ukuran mikrostruktur yang besar disebabkan oleh adanya fasa baru yang terbentuk pada pencampuran kalsium pirofospat dan zirkonia. Sedangkan pada proses setelah Solvothermal hanya menghasilkan satu fasa yaitu $\mathrm{Ca}_{2} \mathrm{P}_{2} \mathrm{O}_{7}$ dan tanpa ada fasa lain, meskipun ada prosentasenya kecil. 
Ihsanul Huda, Retno Kusumaningrum, Galuh Sukmarani dan Alfian Noviyanto

\section{Kesimpulan}

Berdasarkan hasil dari penelitian ini bahwa komposit biomaterial Kalsium Pirofospat baik yang berasal dari cangkang telur ayam maupun cangkang telur bebek, setelah proses pencampuran dan pemanasan pada temperatur $1000^{\circ} \mathrm{C}$ dengan penambahan komposit Zirkonia tidak dapat stabil pada fraksi fasanya. Terlihat dari hasil pengujian XRD yang mengalami dekomposisi. Sesuai dengan reaksi kimia $\mathrm{Ca}_{2} \mathrm{P}_{2} \mathrm{O}_{7}+$ $\mathrm{ZrO}_{2}$ dipanaskan pada temperatur $1000^{\circ} \mathrm{C}$ akan bereaksi, fasa yang terbentuk $\mathrm{CaO}_{2}+$ $\mathrm{CaZrO}_{3}+\mathrm{P}_{2(\mathrm{~g})}$ dan fospatnya akan menguap. Selanjutnya $\mathrm{CaO}_{2}$ dipanaskan akan berubah menjadi $\mathrm{CaO}+\mathrm{O}_{2(\mathrm{~g})}$, sehingga $\mathrm{O}_{2}$ akan menguap dan akan menghasilkan produk akhir yaitu berupa fasa $\mathrm{CaO}, \mathrm{CaO}_{2}$ dan $\mathrm{CaZrO}_{3}$

Untuk ukuran mikrostruktur dari biomaterial CPP yang baru mengalami perubahan bentuk menjadi lebih besar dan lebih beraturan dibanding ukuran mikrostruktur sebelumnya. Hal ini disebabkan oleh proses pemanasan $1000^{\circ} \mathrm{C}$ serta penambahan Zirkonia. Untuk studi selanjutnya diperlukan, guna mendapatkan nilai pemanasan yang sesuai yang tidak merubah komposisi kimia pada Kalsium Pirofospat agar dalam memodifikasi Kalsium Pirofospat Zirkonia bisa tercapai. 


\section{BIBLIOGRAFI}

Asri, Lia, Septawendar, Rifki, \& Sunendar, Bambang. (2016). Zirkonia untuk Aplikasi Material Restorasi Gigi. Jurnal Keramik Dan Gelas Indonesia, 25(2), 79-88.

Baidya, Sudip Sukla. (2013). Preparation and Characterization of HydroxyapatiteZirconia Composite.

Bulut, B., Erkmen, Z. E., \& Kayali, E. S. (2016). Biocompatibility of HydroxyapatiteAlumina and Hydroxyapatite-Zirconia Composite including Commercial Inert Glass (CIG) as a Ternary Component. J. Ceram. Sci. Tech, 7(03), 263-276.

Darwis, Darmawan, \& Warastuti, Yessy. (2013). Sintesis dan karakterisasi komposit hidroksiapatit (HA) sebagai graft tulang sintetik. Jurnal Ilmiah Aplikasi Isotop Dan Radiasi, 4(2).

Ediati, Ratna, Mudjahid, Muhammad Nadjib, \& Pangastuti, Pradipta. (2015). Sintesis Zif-8 dengan Metode Solvotermal dalam Pelarut Etanol dan Dimetilformamida. Jurnal Sains Dan Seni ITS, 4(1), 15572.

Geuli, Ori, Metoki, Noah, Eliaz, Noam, \& Mandler, Daniel. (2016). Electrochemically driven hydroxyapatite nanoparticles coating of medical implants. Advanced Functional Materials, 26(44), 8003-8010.

Karlina, Elin, Djustiana, Nina, Joni, I. Made, Febrida, Renny, Panatarani, Camellia, \& Zakyah, Akhyar Dyni. (2017). Analisis Mikrostruktur Partikel Zirkoniakalsiasilika ( $\mathrm{ZrO} 2-\mathrm{CaO}-\mathrm{SiO}$ ) Dari Pasir Zirkon Alam Indonesia Menggunakan Metode Spray Pyrolysis. Jurnal Material Kedokteran Gigi, 6(1), 23-32.

Lee, Jae Hyup, Hwang, Chang-Ju, Song, Byung-Wook, Koo, Ki-Hyung, Chang, Bong-Soon, \& Lee, Choon-Ki. (2009). A prospective consecutive study of instrumented posterolateral lumbar fusion using synthetic hydroxyapatite (Bongros $\left.{ }^{\circledR}-\mathrm{HA}\right)$ as a bone graft extender. Journal of Biomedical Materials Research Part A: An Official Journal of The Society for Biomaterials, The Japanese Society for Biomaterials, and The Australian Society for Biomaterials and the Korean Society for Biomaterials, 90(3), 804-810.

Lin, Feng Huei, Liaw, Jen Ren, Hon, Min Hsiung, \& Wang, Cheng Yi. (1995). The effects of $\mathrm{Na} 4 \mathrm{P} 2 \mathrm{O} 7 \cdot 10 \mathrm{H} 2 \mathrm{O}$ addition on the mechanical properties of sintered Ca2P2O7 bioceramic. Materials Chemistry and Physics, 41(2), 110-116.

Pawarangan, I., \& Yusuf, Y. (2018). Characteristics of hydroxyapatite from buffalo bone waste synthesized by precipitation method. IOP Conference Series: Materials Science and Engineering, 432(1), 12044. IOP Publishing.

Rissa, L. V, \& Priatmoko, S. (2012). Sintesis Lapis Tipis Berbasis Nanopartikel Titania Termodifikasi Silika Secara Sol-gel Sebagai Bahan Antifogging. Jurnal Mipa, 35(1). 
Ihsanul Huda, Retno Kusumaningrum, Galuh Sukmarani dan Alfian Noviyanto

Su, Yangyang, Li, Kezhi, Zhang, Leilei, Liu, Shoujie, Yuan, Ye, \& He, Song. (2017). Calcium phosphorus bio-coating on carbon/carbon composites: Preparation, shear strength and bioactivity. Applied Surface Science, 419, 503-511.

$\mathrm{Xu}$, Ye, Wang, Dazhi, Yang, Lan, \& Tang, Honggao. (2001). Hydrothermal conversion of coral into hydroxyapatite. Materials Characterization, 47(2), 83-87.

Zhou, Huan, Hou, Saisai, Zhang, Mingjie, Chai, Hong, Liu, Yang, Bhaduri, Sarit B., Yang, Lei, \& Deng, Linhong. (2016). Synthesis of $\beta$-TCP and CPP containing biphasic calcium phosphates by a robust technique. Ceramics International, 42(9), 11032-11038. 